and the Martian atmosphere remains to be elucidated.

The discrepancy in ${ }^{38} \mathrm{Ar} /{ }^{36} \mathrm{Ar}$ to which we ${ }^{1}$ and Ozima and Wada refer has only been found in EETA 79001 glass, not in Shergotty or the other SNCs (ref. 8). We believe that the observed linearity in the three isotope plot (see figure), which shows the Martian atmosphere coinciding with terrestrial rocks, argues for an
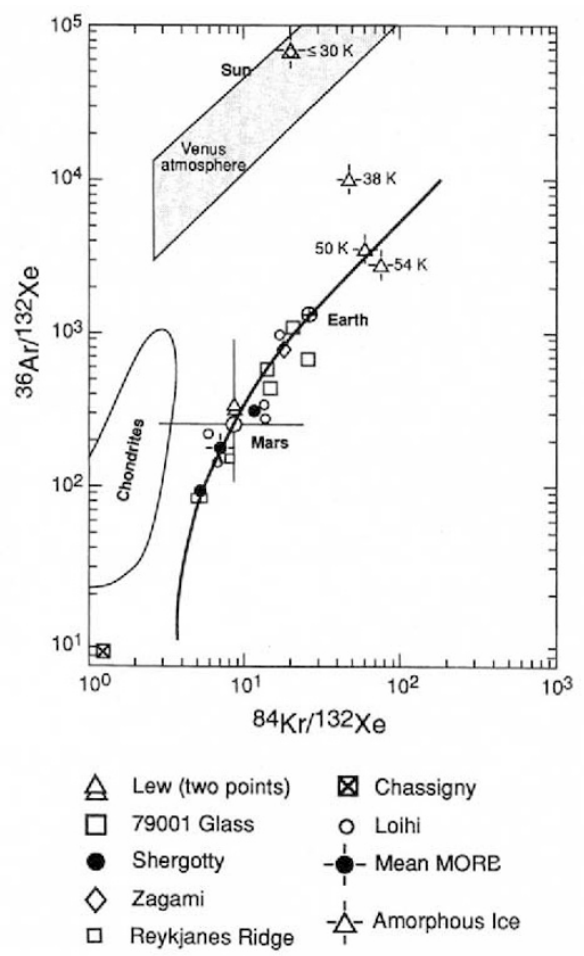

Data from our original Fig. $2 b$ plus Zagami and Lew 88516 (see text) plotted with a true mixing line drawn through the points for the atmospheres of Mars and Earth.

atmospheric value of ${ }^{38} \mathrm{Ar} /{ }^{36} \mathrm{Ar}$ on Mars that is terrestrial $(=$ meteoritic $=$ cosmic).

We stress that we are pulling together various disparate data in the figure, representing several different sources and processes for the trapping of gases. For example, the SNC meteorites have had at least some fraction of the martian atmospheric gases they contain emplaced by shock ${ }^{9}$. Some of these gases could have been contributed by the impactor that dislodged the SNCs from Mars. (Note that some SNC data fall above the Mars atmosphere point in the figure, whereas all the terrestrial rocks appear below the Earth's atmosphere.) The trapping of gases in amorphous ice proceeds by adsorption in a microporous $\operatorname{solid}^{10}$. The gas-melt partitioning proposed for the terrestrial rocks by Ozima and Wada will not encompass these two cases, nor will it account for Chassigny because of the unique character of the latter's xenon isotopes, compared with other SNCs (ref. 8), nor will it explain the enhancement of radiogenic isotopes in the martian atmosphere $e^{1,8}$

We find it highly significant that the data in the figure cluster around a mixing line that cannot be directly associated with either the chondritic meteorites or solar abundances (see refs $1,8,11)$. A mixture of gases contributed by comets formed in the UranusNeptune region of the solar nebula and gases from an internal, rocky reservoir offers an attractive alternative. The new noble gas data for submarine basalts ${ }^{2,3}$ support this suggestion. Of the $8 \mathrm{MORB}$ and Loihi samples with ${ }^{20} \mathrm{Ne} /{ }^{22} \mathrm{Ne} \geqslant$ 10.2 , all have values of ${ }^{36} \mathrm{Ar} /{ }^{132} \mathrm{Xe}<500$ (atmosphere values are 9.8 and 1,350, respectively). Partitioning from a common reservoir would not produce this association of isotopic (neon) and elemental (argon/xenon) fractionation, but the appearance of solar-type neon together with highly fractionated heavy noble gases in mantle-derived rocks (the internal reservoir) is exactly what our model predicts ${ }^{1}$.

Nothing in this discussion explains the noble gases on Venus (see figure). If confirmed, however, a newly discovered $^{12}$ member of the long-sought Kuiper Comet-belt ${ }^{13}$ would be an example of the icy planetesimals that could account for the Venus abundances ${ }^{1}$.

We continue to believe that our original hypothesis is viable, but it is clear that more data are required to test it. As we have said before ${ }^{1,14}$, noble gas abundances and isotope ratios from dynamically new comets (as well as better data from Mars, Venus and submarine basalts) are essential.

\section{Toblas Owen}

Institute for Astronomy,

University of Hawaii,

Honolulu,

Hawaii 96822, USA

Akiva Bar-Nun

Department of Geophysics and

Planetary Sciences,

University of Tel-Aviv,

Tel-Aviv,

Israel

1. Owen, T., Bar-Nun, A. \& Kleinfeld, I. Nature 358 43-45 (1992)

2. Hiyagon, H. et al. Geochim. cosmochim. Acta 56 , 1301-1306 (1992).

3. Honda, M. et al. Geochim. cosmochim. Acta (in the press).

4. Kirsten, T. J. geophys. Res. 73, 2807-2810 (1968)

5. Ozima, M. \& Alexander, E. C. Jr Rev. Geophys. Space Phys. 14, 385-390 (1976)

6. Ott, U., Löhr, H. P. \& Begemann, F. Meteoritics (Abstr.) 23, 295-296 (1988)

7. Ott, U. Meteoritics (Abstr.) 27, 271 (1992)

8. Ott, U. Geochim. cosmochim. Acta 52, 1937-1948 (1988)

9. Bogard, D. D., Hörz, F. \& Johnson, P. H. J. geophys. Res. 91, E99-E114 (1986)

10. Bar-Nun, A., Kleinfeld, I. \& Kochavi, E. Phys. Rev. B38 7749-7754 (1988)

11. Ott, U. \& Begemann, F. Nature 317, 509-512 (1985)

12. Jewitt, D. \& Luu, J. X. Int. Astron. Union Circular 5611 (1992)

13. Kuiper, G. P. in Astrophysics (ed. Hynek, J. Allen) 357-424 (McGraw-Hill, New York, 1951).

14. Owen, T., Bar-Nun, A. \& Kleinfeld, I. in Comets in the Post-Halley Era (eds Newburn, R. Jr, Neugebauer, M. \& Rahe, J.) 429-438 (Kluwer, Dordrecht, 1991).

\section{More protein talk}

SIR - Gonnet and Benner ${ }^{1}$ have searched for the longest English word in the protein sequence databank. But what of other languages? Given that the ownership of the longest peptide-word will undoubtedly become a source of intense national pride, I thought it wise to investigate.

I performed a similar analysis to Gonnet and Benner using a standard hashing algorithm to search the SwissProt databank $^{2}$ with a multilingual word list of 1.3 million words from Danish, Dutch, English, Finnish, French, German, Italian, Norwegian, Spanish, Swedish and some Esperanto. Words were considered only if they incorporated no accented letters or other special characters.

Apart from English, four of the other languages provided nine-letter words: ansvarlig (a Danish word meaning 'liable') in entry HX_YEAST at position 85 ; haletante (French for 'breathless') in K1C0_XENLA at 145; saltsilda (Norwegian for 'salted herring') in PAI1 BOVIN at 271, and stillassi (the perfect subjunctive of the Italian word stillare 'to drip') in STE2__YEAST at 207. The most apt nine-letter word was salasivat, PEHX_ERWCH at 10, the past tense of salata, Finnish for 'to keep hidden' or 'to encode'.

Although I did not find any other English words of nine letters or more in SwissProt, the search did turn up a 10-letter Italian word, annidavate, at position 45 in databank entry PHEA. FREDI (C-phycoerythrin $\alpha$-chain from Fremyella diplosiphon). The word is from the past imperfect tense of the word annidare, meaning 'to nest'.

An honourable mention must also go to the 10-letter American-English word Wallawalla (the language of the Shahaptian people of southeast Washington or Oregon), and the Dutch word tariefklas (literally 'tariff class') which are found reversed in the databank at position 18 of BVGB_BORPE and position 938 of ITA4_HUMAN, respectively.

The race is now on for the next longest word. How long will we have to wait before Germany finally scoops the honours with the possible 27-letter peptide-word for 'social sciences': Gesellschaftswissenschaften?

\section{David Jones}

Biomolecular Structure and Modelling Unit,

Department of Biochemistry and Molecular Biology,

University College,

London WC1E 6BT, UK

1. Gonnet, G. H. \& Benner, S. A. Nature 361, 121 (1993). 2. Bairoch, A. \& Boeckmann, B. Nucleic Acids Res. 19 2247-2249 (1991). 